\title{
Pharmacist-documented interventions during the dispensing process in a primary health care facility in Qatar
}

This article was published in the following Dove Press journal:

Drug, Healthcare and Patient Safety

27 November 2009

Number of times this article has been viewed

\author{
Richard Hooper' \\ Abdullah Adam ${ }^{2}$ \\ Nadir Kheir ${ }^{3}$ \\ 'Medical Services Department, \\ ${ }^{2}$ Pharmacy Department, Medical \\ Services, Qatar Petroleum, Doha, \\ Qatar; ${ }^{3}$ Qatar University, College \\ of Pharmacy, Doha, Qatar
}

Correspondence: Nadir Kheir Asst Professor and Founding Chair of Clinical Pharmacy and Practice, College of Pharmacy, Qatar University, PO Box 27I3, Doha, Qatar Tel +974485 |95।

Fax +9744930449

Email nadirk@qu.edu.qa
Objectives: To characterize prescribing error interventions documented by pharmacists in four pharmacies in a primary health care service in Qatar.

Methods: The study was conducted in a primary health care service in the State of Qatar in the period from January to March 2008. Pharmacists in four clinics within the service used online, integrated health care software to document all clinical interventions made. Documented information included: patient's age and gender, drug therapy details, the intervention's details, its category, and its outcome. Interventions were categorized according to the Pharmaceutical Care Network Europe Classification of drug-related problems (DRP).

Results: The number of patients who had their prescriptions intercepted were $589(0.71 \%$ of the total 82,800 prescriptions received). The intercepted prescriptions generated 890 DRP-related interventions (an average of 1.9\% DRPs identified across the four clinics). Fifty-four percent of all interventions were classified as drug choice problems, and $42 \%$ had safety problems (dose too high, potential significant interaction). The prescriber accepted the intervention in $53 \%$ of all interventions, and the treatment was changed accordingly. Interventions as a result of transcription errors, legality and formulary issues were eliminated from this study through the use of computerized physician order entry (CPOE).

Conclusions: Documenting and analyzing interventions should be a routine activity in pharmacy practice setting in primary health care services. Educational outreach visits and other strategies can improve prescribing practices and enhance patient safety.

Keywords: pharmacists, interventions, prescribing errors

\section{Introduction}

Pharmacists are gradually extending their professional roles, slowly shifting their attention from the passive dispensing of medications to actively caring for their patients. This shift of focus has occurred over many years with different degrees of success and intensity. The impact of the ideals of pharmaceutical care on the change of pharmacy and on its new ethical paradigm cannot be underestimated. ${ }^{1}$ However, the publication in 2000 of the report To Err Is Human: Building a safer health system and others such as An Organization with a Memory and A Spoonful of Sugar contributed significantly to drawing attention to the problems associated with pharmacotherapy and stimulated research and discussion about patient safety issues. ${ }^{2-4} \mathrm{~A}$ key role of pharmacists in ensuring the safety of medications prescribed and dispensed to patients emerged. ${ }^{1}$ At around the same period of time, Johnson and Bootman published a landmark article in which they estimated the annual cost of adverse effects of ambulatory drug use in the United States to be US\$76 billion, equaling the annual cost for procuring drugs. The Medical Protection 
Society in the UK estimates that medication errors account for approximately $20 \%$ of all clinical negligence claims against doctors in both primary and secondary care. ${ }^{5}$ These significant events helped to bring both the issue of patient safety and the potential role of the pharmacist in enhancing patient safety to the forefront. ${ }^{6}$

Clinicians are not good at following recommendations for best practice and implementing guidelines resulting in underuse, overuse, and misuse of drugs. ${ }^{7}$

Pharmacists are placed in an excellent position to promote rational use of medicines (ie, prescribing, dispensing, and use). Rational use of medicines requires that patients receive medications appropriate to their clinical needs, in doses that meet their individual requirements, for an adequate period of time, and at the lowest cost to them and/or their community. ${ }^{8}$ The positioning of pharmacists at crucial stages in the drug use process (be it in an outpatient dispensary, a community pharmacy, or beside the patient's bed in a hospital after the drug has been prescribed) allow them to play a vital role in rationalizing drug use through identifying, preventing, and resolving drug-related problems (DRPs). Medication errors (defined as any preventable event that may cause or lead to inappropriate medication use or to patient harm) are the most prevalent form of DRPs, and prescribing errors are the most important source of medication errors. ${ }^{9}$

Since the 1970 s, medication error research started to extend to nonacute care settings, including nursing homes, outpatient pharmacies, and special patient populations. The term "medication misadventuring" was introduced by Manasse who made a strong argument for increased public policy attention to this problem. ${ }^{10}$ Research that addresses prescribing errors has the potential to influence the perception of, and attitude towards, medication errors to produce fundamental changes within the pharmacy, nursing, medical staff, and in the environment they work within.

The literature on prescribing errors is gaining momentum, and the data so far suggests that the problem is not limited to any specific health care environment or defined practice setting. For example, a UK community pharmacy study reported $0.7 \%$ prescribing errors identified, and around $28 \%$ of the identified problems could have resulted in patient harm. ${ }^{9}$ In the hospital setting, pharmacists' interventions were demonstrated in initiating changes to hospitalized patient management which led to cost savings relating to length of stay, readmission, drugs, medical procedures, and laboratory monitoring. ${ }^{11}$

Technology has a promising role in reducing adverse drug events. It has been reported that computerized decision support systems (CDSS) reduced the incidence of over dosage, adverse reactions, and the length of hospital stay. ${ }^{12}$ CDSS were also effective in changing the class of drug prescribed, increasing generic prescribing, and improving activities related to medication management.

Other prescribing error reduction strategies include electronic prescribing (EP) and PDA-based documentation and use. These proved successful in collecting data on DRPs and documenting pharmacist interventions. ${ }^{13}$ Electronic prescribing minimized and sometimes eliminated errors of omission (incomplete scripts), such as missing important patient or prescriber's information. These tools also minimized the occurrence of drug-drug interactions, dosage problems, and inconveniences caused by prescribing a medication that was out of stock. In hospitals, information technology (IT) has proved cost-effective and even reduced mortality rates. ${ }^{14}$

Interventions that are most effective for influencing prescribing practice include feedback, reminders, educational outreach visits, and patient-mediated interventions. ${ }^{15}$

Grindrod and colleagues suggested that for pharmacists to positively impact prescribing practices they should focus on these strategies rather than relying primarily on passive didactics or dissemination of guidelines. ${ }^{16}$

Despite the evidence published so far on prescribing errors, there is still a paucity of research reporting the role of pharmacists in identifying these errors and the prevalence of near-miss incidents in the prescribing process. Indeed, we could find no previously published work to document and bench-mark the problem of prescribing errors or the role played by pharmacists in identifying these errors in primary health care in Qatar, or other countries of the Arabian Gulf region. We believe it is of paramount importance that all pharmacists positioned at the frontline of the drug-use process promote effective reporting and information sharing on the number, types, causes, and consequences of prescribing errors. This could facilitate research that assists in better understanding the root cause of prescribing errors and the development of appropriate process control measures to minimize them. The aim of this study was therefore to characterize and analyze interventions documented by pharmacists in outpatient pharmacies of a primary health care service in Qatar.

\section{Methods}

This prospective, descriptive research project was conducted in four primary health care clinics ( coded A, B, C, and D for the purpose of this study) within a primary health care service in the capital city of the State of Qatar, in the period from January to March 2008. Each of these clinics is supported by an embedded pharmacy team composed of a senior 
pharmacist with wide administrative duties and a number of pharmacists and pharmacy assistants (Table 1). Prior to data collection, pharmacists in the four clinics attended two orientation workshops covering the concepts of DRPs, pharmacy interventions, categorizing intervention, and the documentation process.

Pharmacists used online integrated health care software (TrakCare ${ }^{\circledR}$; InterSystems, Cambridge, MA, USA) to document all interventions made. Documented information included: patient's age and gender, drug therapy details, the intervention details, its category, and its outcome (at prescriber level; at patient level; at drug level). Each intervention made was communicated to the respective prescriber by the intervening pharmacist in person or by phone. Intervention data and their outcomes were retrieved weekly from the respective clinics' software and entered by a research team member in a dedicated Excel spreadsheet (Microsoft Corp., Redmond, WA, USA) for preliminary analysis and data cleaning. The data was then exported to SPSS software (version 17; SPSS Inc., Chicago, IL, USA) for final analysis. All interventions and their outcomes were reviewed later by two members from the research team (Abdullah Adam, and Nadir Kheir), who also categorized the intervention as per the Pharmaceutical Care Network of Europe (PCNE) classifications in broad DRP classes. The outcome of the intervention (on prescriber or patient level) was recorded in the pharmacy's software (as intervention; a) approved and treatment changed, b) approved and no treatment was changed, c) rejected, information only. Medication counseling, referral made, written information provided was also noted).

\section{Data analysis}

Each intervention was considered a potential DRP and was categorized using an adaptation of the Pharmaceutical

Table I Demographics of the clinics

\begin{tabular}{llll}
\hline Clinic & No of shifts & Pharmacy staff & $\begin{array}{l}\text { Average } \\
\text { Rx/day }\end{array}$ \\
\hline A & 2 & $\begin{array}{l}\text { Four pharmacists, one } \\
\text { assistant pharmacist }\end{array}$ & 150 \\
B & 2 & $\begin{array}{l}\text { I2 pharmacists, one } \\
\text { assistant pharmacist }\end{array}$ & 450 \\
C & 2 & $\begin{array}{l}\text { Six pharmacists, one } \\
\text { assistant pharmacist }\end{array}$ & 280 \\
D & 2 & $\begin{array}{l}\text { Four pharmacists, one } \\
\text { assistant pharmacist }\end{array}$ & 270 \\
\hline
\end{tabular}

Notes: All pharmacies had two shifts per working day except the weekend (Saturday where there was I shift only). Fridays are public holidays. Clinic B has several other smaller associated pharmacy dispensaries distributed at different locations and intervention data was collected in all its branches.
Table 2 The pharmaceutical care network Europe classification of DRPs

\begin{tabular}{ll}
\hline Category & Subcategory \\
\hline & Dosing problem \\
Drug interactions & Drug not administered (drug use problem) \\
Safety problem & Wdverse drug reaction \\
& Inappropriate drug \\
& Inappropriate form \\
& Duplicate therapy \\
& Contraindication \\
Drug choice problem & No indication \\
& No drug but clear indication \\
& Need for education, therapy failure, \\
dissatisfaction with treatment
\end{tabular}

Care Network Europe Classification of DRPs (revised 01-05-06 V5.01) (Table 2). ${ }^{17}$ Means and percentages were calculated for the numbers and outcomes of interventions, including other variables where applicable. Correlations were expressed as Pearson's correlation coefficient $(r)$ and statistical significance was set at $P<0.05$.

The data were exported from the clinics' integrated health care software into the study Excel spreadsheet and then to the SPSS software for analysis.

The study looked at interventions made without reference to the identities of specific patient, doctor, or pharmacist. The study was approved by the Department of Medical Services at the primary health care facility in Doha, no direct patient involvement (eg, interviews) were involved and, no personal details were published.

\section{Definitions}

1. Our working definition for a pharmacy intervention was: 'any contact made by a pharmacist during the dispensing process with a prescriber or a patient and that was aimed at rationalizing drug prescribing or use'.

2. We adopted the PCNE's definition of DRPs which states that a DRP is 'an event or circumstance involving drug therapy that actually or potentially interferes with desired health outcomes. ${ }^{17}$

Furthermore, we considered a prescribing error as any prescribing decision which results, or had the potential to result in, an unintentional significant reduction in the probability of treatment being timely and effective, or an increase in the risk of patient harm. 
Table 3 Demographics of the patients who had prescriptions with errors

\begin{tabular}{ll}
\hline Criterion & Statistic \\
\hline Age & $33.6 \pm 13.3$ years \\
Sex & 478 males $(80 \%)$ \\
& 116 females $(20 \%)$ \\
Average no of items per visit & $3.6 \pm 4.7$ \\
\hline
\end{tabular}

\section{Results}

Of a total of 82,800 patients presenting with prescriptions in a three-month period, there were 594 patients (Table 3) whose prescriptions were intercepted for suspected errors $(0.72 \%)$. The total number of DRP-related interventions made in the study period was 890 interventions. Table 4 provides the distribution of all interventions across clinics (total prescriptions dispensed, number and percentage of intervention per clinic and in total). $10.8 \%$ of the total prescriptions intercepted were for children who were aged five years or younger and 3.5\% were for children who were aged between six to 12 years. Prescriptions for patients who were 60 years or older were $3 \%$ of the total prescriptions intercepted, and the majority ( $83 \%$ of the total) was for patients whose ages lie between 13 and 59 years. Overall, the percentage of errors intercepted ranged from 0.4 to $1.9 \%$ of the total prescriptions dispensed. The mean across all clinics was $1.7 \%$.

Figure 1 shows the classes of interventions made based based upon the PCNE classification of DRPs. Over half of all errors were related to drug choice problems, followed by drug safety problems. When drug choice problems were further analyzed (Figure 2), prescribing inappropriate drug therapy contributed $39 \%$ of the total, followed closely by duplicate therapy (32\%). In interventions classified as safety problems, $51 \%$ of the interventions (ie, 188 interventions from a total of 363) were related to dosing errors (Figure 3).

Intervention outcomes were categorized using the PCNE classification. At the prescriber's level, 53\% of all interventions made across the four clinics were accepted and treatment modified. The outcome of the interventions that were accepted by the prescriber at the drug level are summarized in Figure 4. In 35\% of the interventions, a dose was changed, and in 20\% the drug was changed.

At the patient level, written information was provided to the patient in over $60 \%$ of the interventions made, and medication counseling (over and above the routine instructions given at the dispensing window) took place in $24 \%$ of all interventions in this category (Figure 5). At the drug level, dosage change was the most documented outcome (Figure 6).

\section{Discussion}

Safe patient care requires safety-conscious individuals at the frontline to promote effective reporting and learning systems, to develop systems that facilitate information sharing about the number, types, causes, and consequences of errors, facilitate research in order to have a better understanding of the extent and causes of possible patient harm, and to develop appropriate solutions. ${ }^{17}$ Prescribing errors are a universal problem with similar potential impact on patients' safety and quality of care.

To be most effective and better influence prescribing, pharmacists require clinical knowledge and a set of technical and social skills to underwrite competency so as to negotiate issues relating to best-practice in prescribing with clinicians. Our anecdotal experience suggests that pharmacists need to embed themselves authoritatively within the clinical team in order to develop a mutual respect. In such a relationship they might develop an understanding of the complex cognitive processes and emotions associated with clinician prescribing. In the clinical setting involved in this study, the senior clinical pharmacists complete the dual authoritative roles of Medical Pharmacy Advisor (MPA) to the regional Primary Health Care Team (PHCT) and as the Chairperson of the Drugs and Therapeutics sub-committee of the Corporate Clinical Governance Committee. We believe that pharmacists might achieve better acceptance of drug interventions by

Table 4 Distribution of documented intervention across all clinics

\begin{tabular}{lllll}
\hline Clinic & $\begin{array}{l}\text { Average daily } \\
\text { prescriptions }\end{array}$ & $\begin{array}{l}\text { Prescription over } \\
\text { three months }\end{array}$ & $\begin{array}{l}\text { Total no of interventions } \\
\text { (\% of total intervention*) }\end{array}$ & $\begin{array}{l}\text { \% Errors } \\
\text { intercepted }\end{array}$ \\
\hline A & 150 & 10,800 & $203(22 \%)$ & 1.9 \\
B & 450 & 32,400 & $457(53 \%)$ & 1.5 \\
C & 280 & 20,160 & $155(17 \%)$ & 0.8 \\
D & 270 & 19,440 & $75(8 \%)$ & 0.4 \\
Total & 1150 & 82,800 & $890 *$ & 1.7 \\
\hline
\end{tabular}




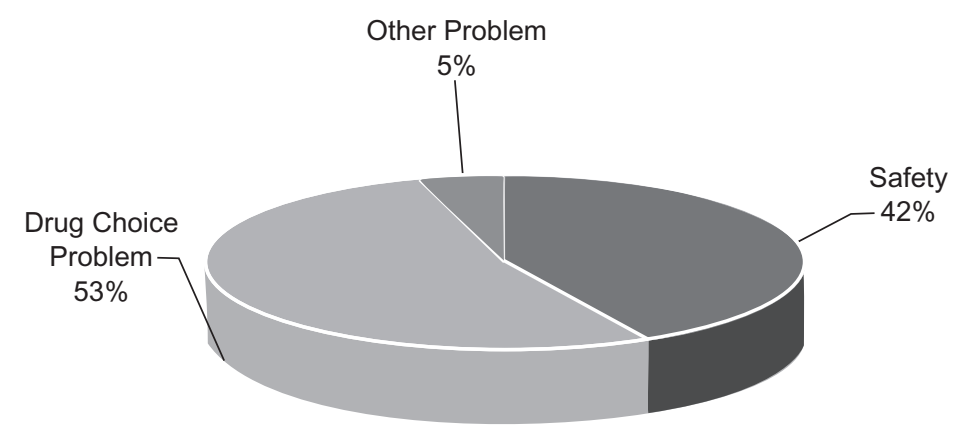

Figure I Interventions: All categories.

clinicians if they reference these interventions to previous, joint professional development sessions and to published literature that is normally resourced by clinicians such as American Family Physicians STEPS collection (freely accessible at: http://www.aafp.org/afp/steps).

This study provides an insight into the potential role of pharmacists in promoting rational drug use in Qatar. It also provided evidence of the magnitude of avoidable prescribing errors that pharmacists could intercept in outpatient pharmacies. The calculated figure of $1.7 \%$ prescriptions with an error is more than double that reported in the UK, ${ }^{13}$ but it is significantly smaller than figures reported elsewhere (Sayer and colleagues, ${ }^{18}$ and Leemans and colleagues ${ }^{19}$ ) who reported $12.4 \%$ and $4.1 \%$ prescribing errors, respectively. However, several reasons for these differences in prevalence could be noticed, not the least in importance was the location of the studies (community/private pharmacies versus pharmacies embedded within primary health care setting) and the fact that transcription errors, prescription legal issues and formulary issues were eliminated from our study through the full use of a CPOE, a factor which must have had huge impact on the number of intercepted errors.

Overall, drug choice problems and drug safety problems featured high in the list of prescribing errors identified. Considering the daily workload and the reality of the pharmacists' priorities (ie, serving patients comes before documenting for the purpose of the study), we think the outcome in terms of documented interventions reported in these three months, while realistic, might be underestimating the real numbers of DRPs in the clinics involved. This could be due to documentation fatigue among the study pharmacists despite an effort to continuously keep motivating them to document each intervention they made. We have included interventions on the level of the patients in this analysis to have a feeling of the role that could be played by the pharmacist engaging in patient education when the need to do so was identified. In most of the cases involving patients, education materials were given out, along with counseling. These strategies are

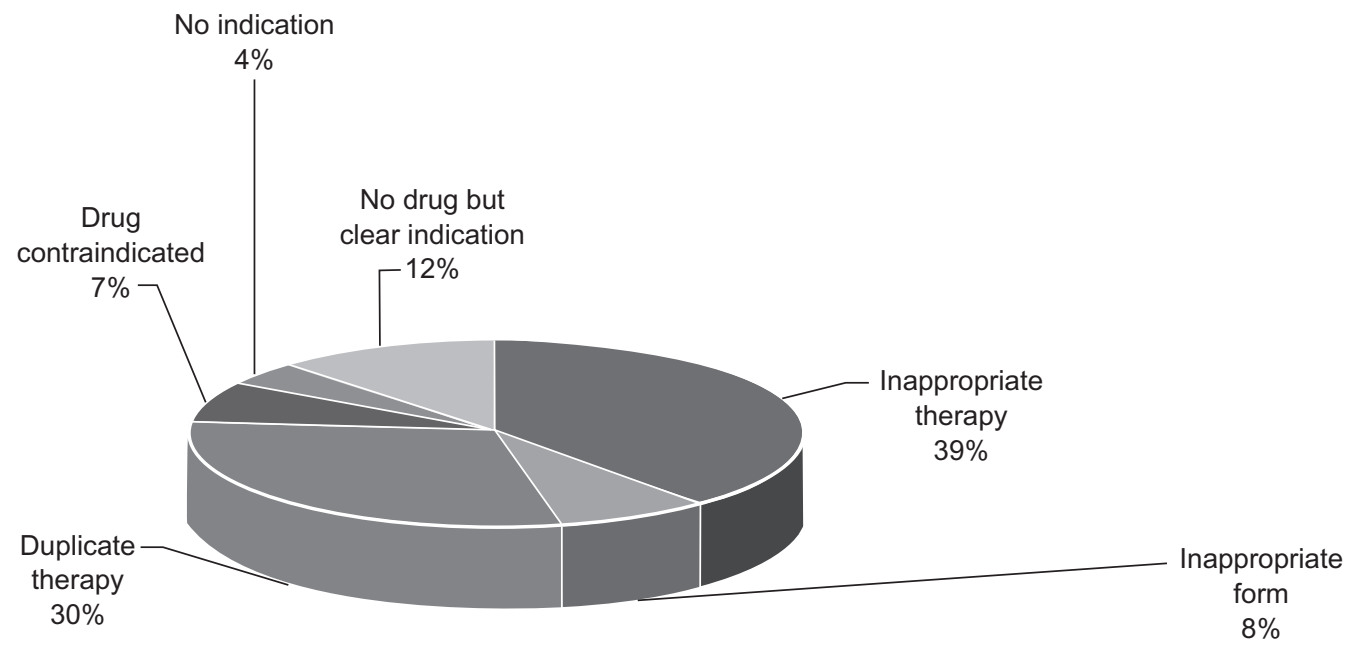

Figure 2 Drug choice problem category (\% contribution). 


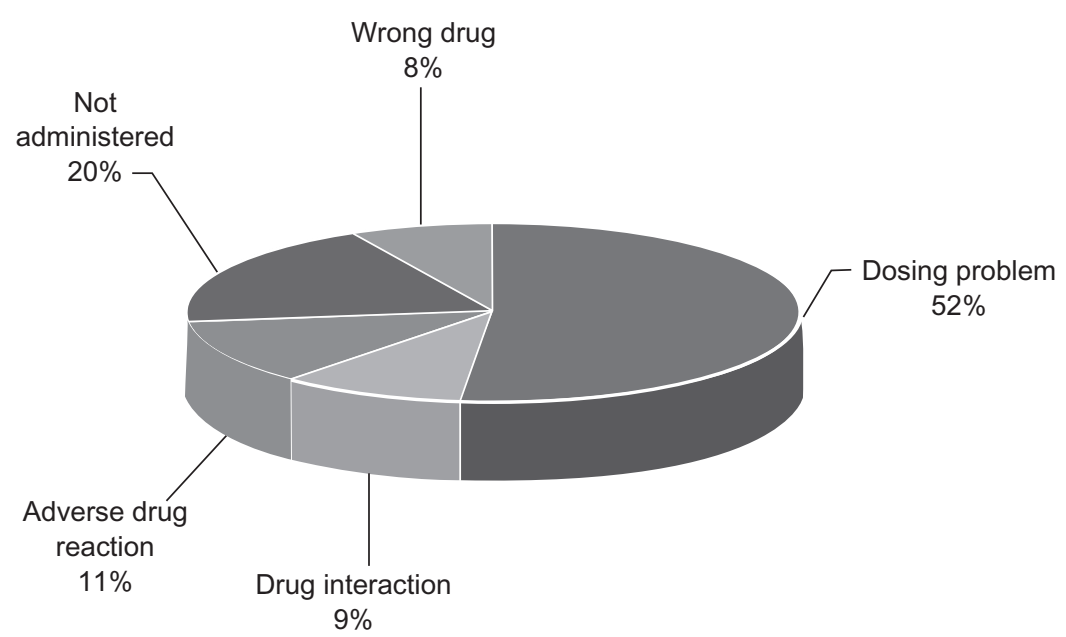

Figure 3 Safety category (Total 363).

expected to improve health outcomes and enhance patient compliance with drug therapy.

Interventions that were more likely to be accepted by the prescribing physicians were those involving dosage errors, duplicate therapy, and drug choice problems, in that order. We have not attempted to trace the fate of rejected interventions in this study. In the absence of a structured validation process we were unable to investigate the basis of rejected interventions. However, such an understanding is critical to the success of DRP intervention programs. Considering the large proportion of rejected interventions, it might be reasonable to assume that a percentage of those interventions made and rejected were actually correct and well-founded. We did not ascertain whether the intercepted prescriptions were dispensed despite suspected errors. If this is the case, then it might suggest an inability of the pharmacists concerned to engage into constructive dialogue with the prescribing physicians, despite having evidence that should have supported changing the therapy. Dispensing a prescription that could have an error raises significant ethical issues relating to the pharmacist's Hippocratical obligation towards beneficence and nonmalfeasance (the responsibility to do good and the duty to do no harm). In general terms, dispensing a prescription that is suspected to be erroneous violates these basic ethical principles.

We found no association between the pharmacists' characteristics (ie, gender, age, and years of experience) and the number of interventions made or documented. This should not be surprising, since many other important factors might contribute to the ability of pharmacists to identify errors. These factors, such as the individual pharmacist's motivation, interest, and clinical knowledge, are difficult to assess

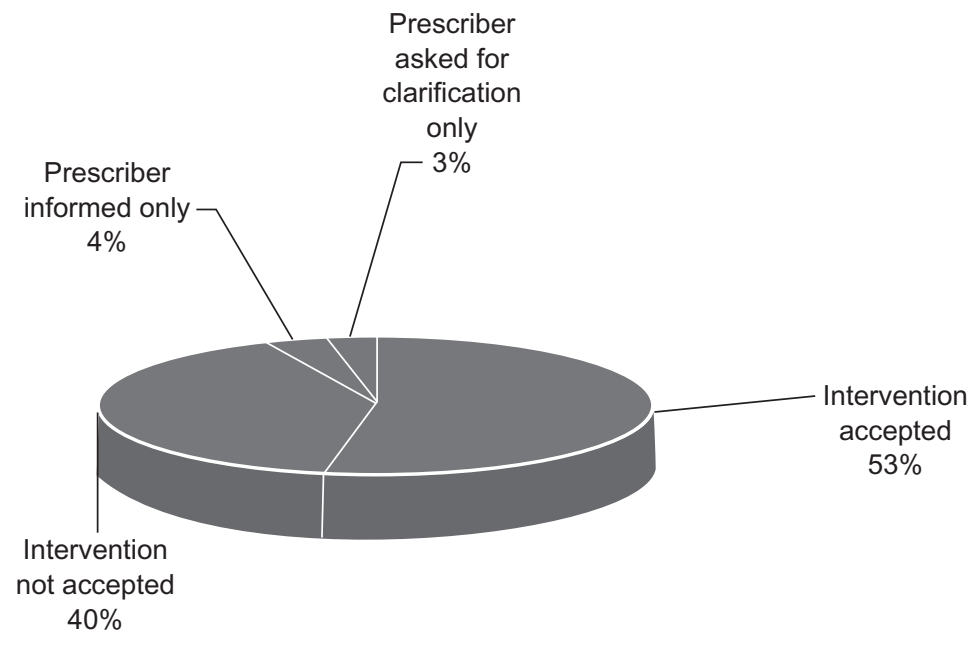

Figure 4 Intervention outcome at prescriber level (Total 448). 


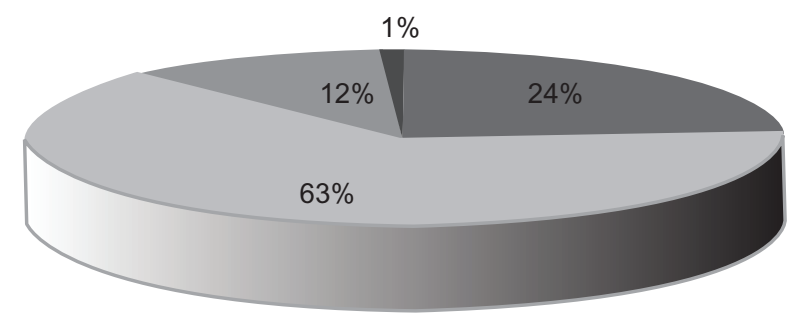

\section{Medication counseling}

Written information provided

Patient referred to prescriber

Others at patient level

Figure 5 Intervention outcomes at patient levels (Total 270).

especially as they fall beyond the scope of the current project, while they could have significantly more influence than other demographics. We were unable to assess the association between errors identified (or accepted/rejected) with the clinician's characteristics for logistical and ethical reasons.

The findings of this study should stimulate further research into the root cause for prescribing and medication errors. The results of such research should promote the development of focused continuing education and training material that would specifically address gaps and safety risks in the prescribing process. This material should be delivered in ways that have been shown to improve prescribing behavior and should be extended to both physicians and pharmacists in a multidisciplinary environment.

Finally, it should be pointed out that no retrospective validation process was carried out by an independent reviewer on the interventions made or those rejected to ascertain grounds for rejection in this study. While accepted interventions carry an inherent validation by both the intervening pharmacist and the prescribing physician, the absence of validation targeting those interventions which were rejected by the prescribers remains a limitation in this study. Additionally, we have not made any attempt to classify the interventions beyond the PCNE classification system into broad DRP types. No classification based on potential 'harm' or seriousness of the prevented DRPs was made.

\section{Conclusions}

Documenting and analyzing interventions should be a routine activity in pharmacy practice of primary health care services Progressive pharmacists are recognizing that this is only the first step in the process of improving patient safety. The real challenge is to work with clinicians to develop multiple

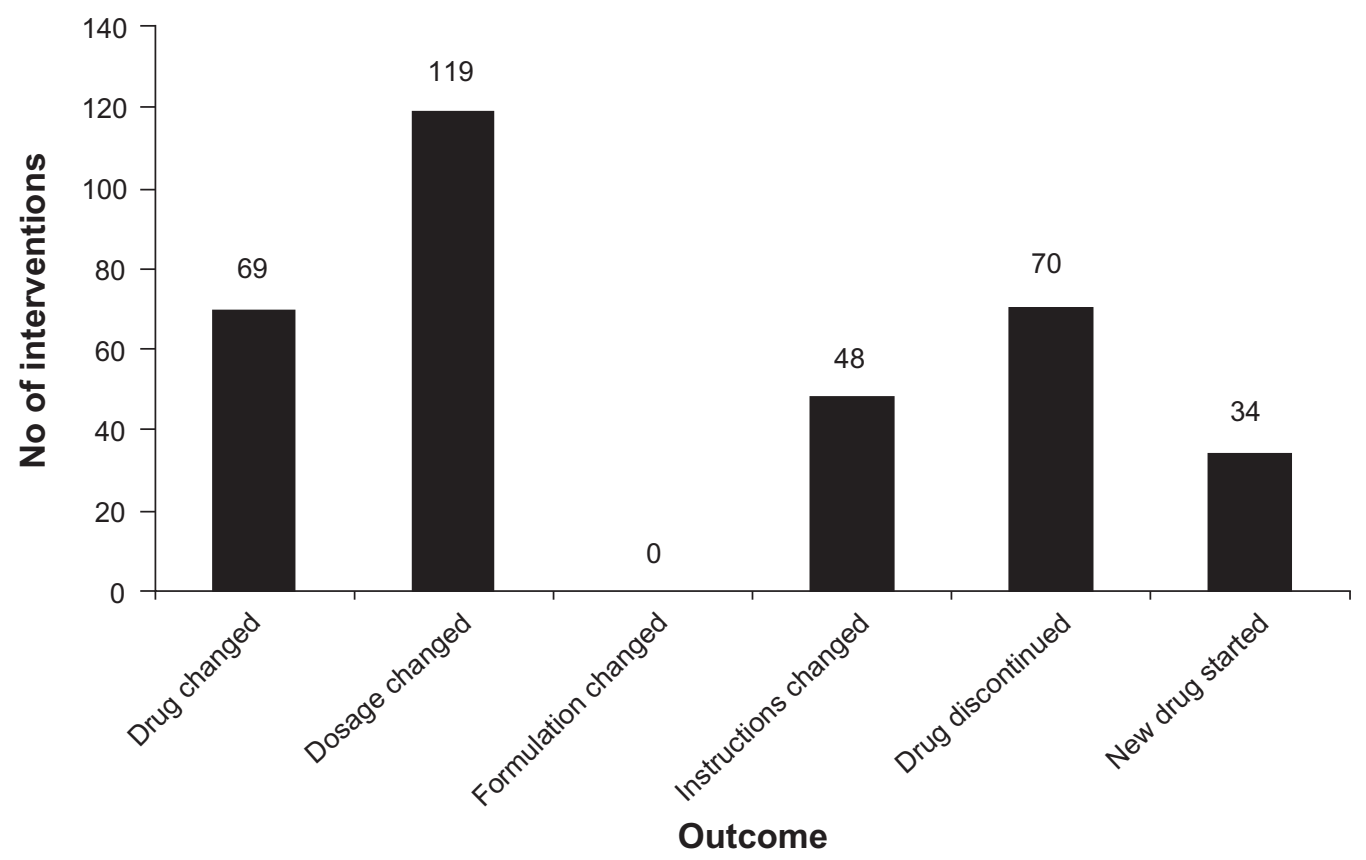

Figure 6 Intervention outcome at drug level. 
channel interventions to better translate the exposure of clinicians to incontrovertible evidence into effect. ${ }^{20}$

\section{Acknowledgements}

Dr Adil Yousif, Statistics Department at Qatar University, for his input in bivariate analysis (pharmacists' characteristics with interventions).

\section{Disclosures}

This research received no specific grant from any funding agency in the public, commercial, or not-for-profit sectors.

\section{References}

1. Hepler CD, Strand LM. Opportunities and responsibilities in pharmaceutical care. Am J Hosp Pharm. 1990;47(3):533-543.

2. Kohn LT, Corrigan JM, Donaldson MS. To Err is Human: Building a safer health system. Washington, D.C: National Academy Press; 2000.

3. Department of Health. A Spoonful of Sugar: Medicines Management in NHS Hospitals. London, UK: Audit Commission Publications; 2000.

4. Department of Health Expert Group. An Organisation with a Memory: Report of an Expert Group on Learning from Adverse Events in the NHS. London, UK: The Stationery Office; 2001.

5. Medical Protection Society. Safe prescribing. 2009. Available from: http://www.medicalprotection.org/ireland/factsheets/safe-prescribing. Accessed on November 11, 2009.

6. Johnson JA, Bootman JL. Drug-related morbidity and mortality and the economic impact of pharmaceutical care. Am J Health Syst Pharm. 199;54(5):554-558.

7. Chassin MR, Galvin RW. The urgent need to improve health care quality. Institute of Medicine National Roundtable on Health Quality. JAMA. 1998;280:1000-1005.

8. WHO Conference of Experts on the Rational Use of Drugs. Nairobi, Kenya: World Health Organization; 1985.
9. Flynn EA, Barker KN. Medication error research. In: Cohen MR, editors. Medication Errors. Washington, D.C: American Pharmaceutical Association; 1999. p. 6.1-6.30.

10. Manasse HR. Medication use in an imperfect world: drug misadventuring as an issue of public policy, Part 1. Am J Hosp Pharm. 1989;46(5): 929-944.

11. Hawksworth G, Corlett A, Wright D, Chrysty H. Clinical pharmacy interventions by community pharmacists during the dispensing process. Br J Clin Pharmacol. 1999;47(6):695-700.

12. Dooley MJ, Allen KM, Doecke CJ, et al. A prospective multicentre study of pharmacist initiated changes to drug therapy and patient management in acute care government funded hospitals. $\mathrm{Br} \mathrm{J}$ Clin Pharmacol. 2004;57(4):513-521.

13. Grindrod KA, Patel P, Martin JE. What interventions should pharmacists employ to impact health practitioners' prescribing practices? Ann Pharmacother. 2006;40:1546-1557.

14. Raybardhan S, Balen RM, Partovi N, et al. Documenting drug-related problems with personal digital assistants in a multisite health system. Am J Health Syst Pharm. 2005;62(17):1782-1787.

15. Amarasingham R, Plantinga L, Diener-West M. Clinical information technologies and inpatient outcomes. Arch Intern Med. 2009;169(2):108-114.

16. Grindrod K, Patel P, Martin J. What interventions should pharmacists employ to impact health practitioners' prescribing practices? Ann Pharmacother. 2006;40:1546-1557.

17. van Mil JWF, editor. Proceedings of the International Working Conference on Outcomes Measurements in Pharmaceutical Care. Pharmaceutical Care Network Europe (PCNE). Hillerød, Denmark: January, 1999;84: 26-29.

18. Sayers YM, Armstrong P, Hanley K. Prescribing errors in general practice: a prospective study. Eur J Gen Pract. 2009;15(2):81-83.

19. Leemans L, Veroeveren L, Bulens J, et al. Frequency and trends of interventions of prescriptions in Flemish community pharmacies. Pharm World Sci. 2003 Apr;25(2):65-69.

20. Davis D, Evans M, Jadad A, et al. The case for knowledge translation: shortening the journey from evidence to effect. BMJ. 2003;327: $33-35$.
Drug, Healthcare and Patient Safety

\section{Publish your work in this journal}

Drug, Healthcare and Patient Safety is an international, peer-reviewed open-access journal exploring patient safety issues in the healthcare continuum from diagnostic and screening interventions through to treatment, drug therapy and surgery. The journal is characterized by the rapid reporting of reviews, original research, clinical, epidemiological and

\section{Dovepress}

post-marketing surveillance studies, risk management, health literacy and educational programs across all areas of healthcare delivery. The manuscript management system is completely online and includes a very quick and fair peer-review system. Visit http://www.dovepress.com/ testimonials.php to read real quotes from published authors. 